\title{
INTEGRACIÓN Y RESISTENCIA A LA ASIMILACIÓN DEL TEXTO LITERARIO EN LOS MENSAJES HIPERCODIFICADOS. KIPLING EN LA PUBLICIDAD Y EL ÁLBUM ILUSTRADO.
}

\author{
INTEGRATION AND RESISTANCE TO ASSIMILATION OF \\ LITERARY TEXTS IN HYPERCODIFIED MESSAGES: KIPLING \\ IN ADVERTISING AND PICTUREBOOKS ${ }^{1}$.
}

José Manuel Trabado Cabado

Universidad de León

\section{ABSTRACT}

This paper aims to study in a conceptual frame called «liquid culture» two discursive strategies that I have labelled as «integration» and «resistance to assimilation» in which are involved hypercodified messages. Both strategies act in a very different way but they have in common the relationship with remediation and some other process that show the metamorphosis of a literary text. In this case the poem by Kipling titled «If» is studied as a part of TV advertisement and as textual part of a picturebook by Mauro Evangelista tittle Lettera a un figlio. Final conclusions invite to rethink the nature of literary text and the canals of «cultural» circulation in the context of mass culture and new media.

\footnotetext{
${ }^{1}$ El presente trabajo forma parte del proyecto de investigación financiado por la Junta de Castilla y León titulado «Evolución de las formas gráfico-narrativas y su relación con el público lector»/LE066G18
} 
Keywords: Remediation, Hypercodification, liquid culture, Kipling, picturebooks, TV advertisement.

\section{RESUMEN}

En este artículo se pretende estudiar dos estrategias discursivas que he denominado «integración»y «resistencia a la asimilación»en las que se ven involucrados los mensajes hipercodificados dentro de la denominada cultura líquida. Ambas actúan en un sentido diferente, pero poseen en común su relación con la remediación y con otros procesos que muestran la metamorfosis de un texto literario. En este caso se estudia el poema de Kipling titulado «If» que forma parte de un álbum ilustrado y de un anuncio publicitario.

Palabras clave: Remediación, hipercodificación, cultura líquida, Kipling, álbum ilustrado, anuncio de televisión.

Fecha de recepción: 20 de junio de 2019.

Fecha de aceptación: 1 de octubre de 2019.

Cómo citar: Trabado Cabado, José Manuel (2019): «Integración y resistencia a la asimilación del texto literario en los mensajes hipercodificados. Kipling en la publicidad y el álbum ilustrado», en Actio Nova: Revista de Teoría de la Literatura y Literatura Comparada, 3: 506-531. DOI: https://doi.org/10.15366/actionova2019.3.021 


\section{MENSAJES HIPERCODIFICADOS EN EL MARCO DE LA CULTURA LÍQUIDA}

La cultura actual podría definirse como una selva de signos que se va haciendo más espesa paulatinamente. Estos signos poseen la peculiaridad de remitir a otros signos y los textos resultantes acabarán por confeccionarse sobre las ascuas de otros muchos textos. Era algo que ya advertía Séneca y que tiene nombres que van desde la imitación compuesta hasta el término de intertextualidad. El texto nunca ocultó que era un tejido realizado con mimbres de muchos otros. Sin embargo, parecía dado por sentado que existían unos circuitos de circulación bien afianzados en los que determinados mensajes discurrían por un territorio bien delimitado que pertenecía a la esfera conceptual del arte. No obstante, la disolución de jerarquías que separaban la cultura de masas de la alta cultura, así como el cambio de soportes y plataformas de transmisión cultural son fenómenos que han vuelto el panorama mucho más complejo. Surgirán nuevos conceptos como transmedialidad (Gil González: 2012; Scolari: 2013), intermedialidad ${ }^{2}$ y estrategias como la remediación (Bolter y Grusin) que proporcionan un marco teórico y ponen a disposición del estudioso y del fan un utillaje instrumental para abordar esa nueva Babel. La polémica de los que quieren salvaguardar las esencias y la pureza de ciertos lenguajes se reaviva a la sombra de ciertos éxitos musicales y se escuda, también, bajo cierta terminología como apropiación que ve cómo su semántica despliega un sesgo negativo (Young: 2008). Esos híbridos, que no dejan de ser caracterizados como realizaciones artísticas oportunistas, ensamblan piezas de muy diversa procedencia y con una categorización cultural que, a priori, es muy dispar. Es esa disparidad la que genera cierto malestar: cómo es posible que ciertos mensajes artísticos acaben subsumidos en otras realizaciones que algunos catalogan de gusto dudoso. Parte de estas realizaciones presentan, además, la singularidad de integrar un texto artístico en un contexto muy diferente como podría ser, pongo por caso, un anuncio publicitario. El perímetro de ese territorio artístico se difumina, entonces, en una serie de prácticas que ponen en crisis conceptos bien asentados. La yuxtaposición de lenguajes se convierte en una estrategia propicia para conseguir esa amalgama entre el arte elevado y el fin práctico más inmediato que no tiene otro objetivo que vender e incitar al consumo. Bajo esa tendencia propongo a modo de

2 Remito para una visión en profundidad del alcance terminológico y el marco conceptual al trabajo de Sánchez Mesa y Baetens (2017) 
hipótesis utilizar el concepto de integración cuando un texto artístico pasa a formar parte de un mensaje más complejo y colabora en una intención práctica para la que no estaba previsto. En esa operación es posible advertir una erosión de esa función estética que se compensa gracias a lo que podría denominarse un contagio estético al resto del mensaje. Los productos anunciados pueden asumir en una pequeña dosis algo de aquella función estética y acabarán por desarrollar sobre todo un valor emocional. Esas nuevas funciones son, no obstante, coyunturales y pueden tener efectos imprevistos. Es posible que una canción se ponga de moda por formar parte de un anuncio o que alguien llegue a un poema porque formaba parte de un spot publicitario. Esas nuevas fórmulas de circulación cultural pueden desestabilizar ciertos conceptos pero, al mismo tiempo, dotan a los mensajes de un comportamiento dinámico que garantiza la posibilidad de significar en un tiempo en el que las palabras y los signos parecen estar cansados de haberlo dicho todo.

Frente a esta estrategia pueden observarse otras operaciones que actúan en un sentido contrario: los textos artísticos ya no se integran en mensajes de naturaleza diferente obligándoles a propósitos comunicativos espurios; la naturaleza hipercodificada de esos mensajes pone en contacto lenguajes que realzan su efecto estético: tal es el caso de la transformación de mensajes literarios en otros textos como, por ejemplo: el álbum ilustrado. Cuando algún texto literario se usa como base para construir un álbum ilustrado no está supeditado a una nueva función. Su valor y su naturaleza literaria no disminuye un ápice sino que, por el contrario, posibilita un incremento no sólo en su capacidad comunicativa sino también en su efecto estético. En este segundo caso podría verse una «resistencia a la asimiliación» de lo literario por parte de otros lenguajes. Los textos literarios, de naturaleza breve -cuentos, poemas- toman otra dimensión y se legitiman editorialmente como textos autónomos, pero para ello era necesario, antes de nada, la posibilidad de que un texto se pueda desgajar de su contexto inicial.

Para mostrar el funcionamiento de esas dos operaciones que atañen a los mensajes hipercodificados en el marco de una cultura en la que se difumina la oposición arte/no arte propongo ver el diferente comportamiento del poema «If» escrito por Kipling. Ambas realizaciones, anuncio publicitario y álbum ilustrado, son prácticamente coetáneas lo que permite un punto de apoyo desde una perspectiva metodológica. 


\section{El CARÁCTER DESGAJABLE DEL TEXTO LITERARIO:}

Como ya se ha insinuado para que un texto literario forme parte de otro mensaje más complejo ha de ser en cierto modo desgajable del contexto en el que apareció publicado. Un poema, una canción pueden tener una andadura al margen del libro o del álbum musical al que pertenecían. Ese texto de personalidad poderosa pugna, en cierto modo, por evadirse de la presencia de sus semejantes para hablar con una voz diferenciada. Hemos podido leer poemas, escuchar canciones, encontrar relatos en circunstancias azarosas, verlos antologados y espigados del conjunto original en que aparecían. Ese encuentro fortuito habla de cómo se diluyen los lazos comunales del texto que va perdiendo sus relaciones de parentesco con los compañeros con los que vio la luz.

En el caso del poema de «If» sobre el que habrán de pivotar las siguientes páginas pronto pudo advertir Ruyard Kipling que su poema, incluido en la sección titulada «Brother Square Toes» de Rewards and Fairies publicado en 1910, cobraría independencia y que, extraído de su contexto natural de publicación y liberado de las circunstancias que habían propiciado su escritura, iba adquiriendo la cualidad de texto de culto. El propio autor lo había advertido en su autobiografía Sometbing of myself publicada póstumamente en 1937 cuando afirmaba:

Among the verses in Rewards was one set called 'If-', which escaped from the book, and for a while ran about the world. They were drawn from Jameson's character, and contained counsels of perfection most easy to give. Once started, the mechanization of the age made them snowball themselves in a way that startled me. Schools, and places where they teach, took them for the suffering Young - which did me no good with the Young when I met them later. [..] They were printed as cards to hang up in offices and bedrooms; illuminated text-wise and anthologized to weariness. Twenty-seven of the Nations of the Earth translated them into their seven-and-twenty tongues, and printed them on every sort of fabric (2013:111).

El texto tenía en cuenta un episodio histórico protagonizado por Leander Starr Jameson y su incursión militar a finales de 1895 en la República de Transvaal cuyo resultado derivó en una derrota. Frente a ese fracaso, Kipling vio la posibilidad de crear un programa de conducta basado en la templanza y en la necesidad de creer en uno mismo más allá de las vicisitudes coyunturales del éxito y del fracaso. Lo convirtió, pues, en poema y lo integró en su Rewards and Fairies. En cuanto que poema, el texto de Kipling atenuaba su información contextual y permitía una lectura fuera de ese marco histórico y concreto que le había dado 
carta de naturaleza. Dicho de otro modo, el lector no necesitaba esa información para comprender el texto; podría decirse, incluso, que -de haberse hecho explícitas- esas circunstancias harían más difícil la posibilidad de asunción vital por parte del receptor. La mención de un receptor interno al final del poema: «my son» lo dotaba de una intensa emocionalidad al convertirlo en una suerte de comunicación íntima mediante la cual el emisor -asociado así a la figura del padre- dejaba en herencia a su hijo algo valioso: el secreto de una forma de ser y estar en el mundo. El lector asiste como partícipe de ese inmenso regalo. Las características de la enunciación lírica diluían las motivaciones colonialistas que podrían haberse advertido en un texto surgido en esas circunstancias y ese hecho permite su andadura de forma individual y la adquisición de nuevos valores que quizás fuesen extraños a la intención originaria de Kipling. Así se explica que Robert Haven Schauffler en 1931 incluyese este poema en su libro The Junior Poetry Cure: A First-Aid of Verse for Young of All Ages, tal y como indica Nicholas Mazza (2003:61). Se utilizaba este texto para incidir en la necesidad de un comportamiento basado en la deportividad. Sus dos famosos versos: «If you can meet with Triumph and Disaster / And treat those two impostors just the same» dejaban de orbitar en torno a la idea de lo militar para adscribirse a la noción de una serie de valores asociados a lo deportivo. Esa idea de resistencia frente a la adversidad permitía la adquisición de múltiples valores y el poema podía ser reutilizado en contextos sumamente variados con resultados especialmente curiosos como, por ejemplo, el uso que le da Tom Mboya, uno de los líderes fundadores de Kenia, cuando recita este poema en la víspera de las elecciones. Tal y como advierte Alastair Pennycook: «The poet of Anglo-Saxon imperialism had become the poet to inspire African leadership» ${ }^{3}$.

El poema de Kipling fue el preferido por los británicos en la encuesta que realizó la BBC en 1995. Unos años antes, en 1992, su texto fue utilizado en el marco de la Segunda temporada de Los Simpson, en concreto, en el episodio «Old money» emitido el 28 de marzo de 1991. En la revista El Jueves el texto del poema de Kipling fue reproducido íntegramente en la serie Makinavaja de Ivà. Todo ello da una buena muestra del éxito del poema y de su

\footnotetext{
${ }^{3}$ La interpretación de los textos de Kipling desde la perspectiva colonialista sigue siendo ambigua. Por un lado, dirigentes africanos habían asumido el texto de Kipling y se lo habían apropiado para consolidar el sueño de la independencia y la consecución de una identidad; por otro lado, en julio de 2018 estudiantes de la Universidad de Manchester borraron el poema de Kipling que figuraba en los muros de esta universidad por no considerarlo portavoz de sus valores. En su lugar colocaron, el poema de Maya Angelou «Still I Rise». https://www.bbc.com/news/uk-england-manchester-44884913 [10 de mayo de 2019].
} 
capacidad para formar parte de un imaginario colectivo ${ }^{4}$.

Para que esto sucediera era necesario que el poema fuese fácilmente desgajable de su contexto original de publicación. Esa separabilidad y la falta de referencias contextuales marcadas permitían al lenguaje poético ir adquiriendo una serie de valores universales que podían investirse de una profunda emocionalidad asociada a la mención de la palabra «hijo» en la parte final y la prédica de unos valores asumibles por la colectividad en cuanto que no supeditaban todo a la obtención de un éxito que bien podría ser algo meramente circunstancial. La emoción, pues, se aliaba fácilmente con la exposición de una ética que convenía a las más diversas situaciones discursivas. La deportividad, la creencia en uno mismo y en la defensa de unos ideales por encima de las circunstancias adversas servían como acicate para mostrarlo como modelo en el mundo deportivo y en el político. Precisamente esa cercanía a unos valores que encajaban perfectamente en el mundo deportivo explica que el dístico de versos en los que Kipling insta a tratar tanto al triunfo como al fracaso como impostores por igual figure en el acceso a la pista central de

\footnotetext{
${ }^{4}$ El poema de Kipling no solo forma parte de ese imaginario colectivo como mercancía almacenada que está a disposición de todos para ser consumida. Existe una mediación obvia. La asunción de ese poema conlleva un vínculo emocional muy fuerte. Valga recordar la anécdota con la que Juan Cruz recuerda el vínculo establecido con Adolfo Marsillach a través de ese poema. El propio Juan Cruz así lo recuerda:
}

\begin{abstract}
Nuestra extraña amistad, por decirlo así, procede de una anécdota que conté allí esa noche, en el homenaje a Marsillach. Él la supo hace muchos años y mi impresión es que ese hecho que yo le conté había afianzado un cariño que fue mutuo y casi secreto. Cuando yo era un adolescente me aficioné a un poema en particular de Rudyard Kipling, If, en el que el escritor británico recorre las distintas imposturas de la vida para acabar advirtiendo contra el triunfo y contra la derrota, que son los grandes impostores.
\end{abstract}

Copié ese poema, con bolígrafo, en la mampostería de la puerta principal de mi casa; mi madre me obligó a borrarlo. A lo largo del tiempo esas huellas de mi uña sobre el poema siguieron frente a las inclemencias del tiempo y por encima de los sucesivos enjalbegados.

Un día estaba yo en la antesala de la consulta del médico que trataba a mi madre, en el hospital de Tenerife. En una revista que había sobre la mesita hallé una entrevista con Marsillach, a quien yo no conocía personalmente todavía. En esa conversación el gran actor explicaba que uno de sus poemas preferidos era justamente ese de Kipling contra las imposturas. Me levanté, como impulsado por la sorpresa que te dan a veces los recuerdos y me puse a dar vueltas por la antesala solitaria. Hasta que me fijé en uno de los cuadros que tenía colgados el médico. En uno de ellos estaba la transcripción de If, de Rudyard Kipling.

https://blogs.elpais.com/juan_cruz/2013/01/marsillach-y-el-poema-if-de-kipling.html

La importancia del poema de Kipling y su hondo sentido emocional se revelan también en el capítulo «El territorio de la memoria» en su novela autobiográfica Territorio de la memoria. (Cruz, 2016: 65-76). 
Wimbledon. Por esta razón no extraña que tanto Roger Federer como Rafa Nadal fuesen los encargados de recitar el poema de Kipling para promocionar la final del torneo en 2008. Ambos se encargarían de realizar un partido de tintes épicos de casi cinco horas calificado como uno de los mejores de la historia en el que, a la postre, vencería Nadal. Los versos de Kipling, de alguna manera, se habían colado en ese espíritu de lo deportivo y venían a resaltar la pelea contra las circunstancias. Victoria y derrota, también sobre el campo deportivo, eran algo relativo que engrandecía por igual a unos y otros.

\section{LA PUBLICIDAD Y LA FÁBRICA DE RELATOS.}

Curiosamente, un año antes de esta gesta deportiva el texto de Kipling fue utilizado en una campaña publicitaria que anunciaba los productos de la petrolera Repsol. No es una práctica inusual el hecho de que la publicidad acuda a textos literarios para crear una atmósfera cargada emocionalmente o para suscitar en el receptor una respuesta diferente al verse sometido a un estímulo estético. Bastaría recordar anuncios especialmente logrados como el del Seat León que utilizaba el texto de Julio Cortázar «Preámbulo a las instrucciones para dar cuerda a un reloj». Ese texto proyectaba una atmósfera inquietante sobre el anuncio al equiparar el reloj con el automóvil anunciado. «No te regalan un reloj. Tú eres el regalado» finalizaba el texto de Cortázar ${ }^{5}$. El anuncio sugería de forma tácita que ese nuevo modelo poseía una fatal fascinación hasta el punto de adueñarse de sus dueños. Resulta muy interesante comprobar cómo lo ominoso inherente a la narración fantástica resultaba en parte neutralizado por el elemento publicitario para remodelarlo y convertirlo en un poder de atracción. En ese anuncio era el propio Cortázar el que leía el texto que sonaba como voz en

\footnotetext{
${ }^{5}$ Javier Cercas se hace eco la crítica que dos lectores de El País hacían sobre el uso del texto de Cortázar en el anuncio publicitario de Seat. Su contestación se vale de argumentos interesantes en los que se destaca la posibilidad de entender literariamente la publicidad y la apropiación como forma de funcionamiento de la propia literatura: «Algunos de nuestros cineastas más reconocidos, por no hablar de actores y deportistas, filman anuncios televisivos, y nadie considera que hacerlo constituya una indignidad; no entiendo por qué tiene que serlo en el caso de los escritores. De hecho, lo raro no es que un anuncio use las palabras de un escritor, sino que no haya muchos más escritores escribiendo anuncios, puesto que las reglas formales de la publicidad y de la literatura no difieren en lo esencial: al fin y al cabo, la publicidad es también un género literario (o casi) [...] Si la literatura es la primera en apropiarse legítimamente de la literatura, ¿por qué no va a ser legítimo que se apropie de ella la publicidad? Nuestra época padece la superstición de la originalidad, pero cualquier creador no del todo insolvente sabe que nada se crea a partir de la nada, y que la única forma de hacer algo nuevo es asimilando creativamente todo lo que ya se ha hecho: toda literatura de verdad es metaliteratura, porque toda literatura de verdad comporta un diálogo con la tradición (2007). Para una visión en conjunto sobre la relación entre literatura y publicidad recuerdo el trabajo de Asunción Escribano (2011).
} 
off encargada de generar una atmósfera que basculaba hacia la incertidumbre. De otra índole es el spot que anunciaba la «Línea verde» de El Pozo cuya banda sonora utiliza la rumba con la que Manzanita había musicalizado el «Romance sonámbulo» de Lorca. Los cambios operados sobre la naturaleza del texto son muy importantes. Si en el caso anterior la naturaleza del texto proyectaba su atmósfera sobre el núcleo narrativo del texto, en este ejemplo existe una trivialización del mensaje que hace una lectura epidérmica que rescata el concepto de «verde» para aplicarlo a una línea de alimentos que no posee ni colorantes ni conservantes. La rumba había aligerado ya el tremendo dramatismo del poema de Lorca y lo había convertido en algo más festivo pero la publicidad lo asocia a un «ecologismo» que en nada encaja con el sentido original del texto.

La publicidad puede ser entendida así como un discurso prevalente en el marco de una cultura en la que unos discursos fagocitan a otros para instarles a hablar en contextos muy diferentes y con sentidos imprevistos. En ese proceso de constante cita y apropiación las intenciones se modifican sustancialmente y las fronteras que delimitaban el territorio de lo estético se vuelven borrosas. La incorporación de lo literario en la publicidad bien pudiera suscitar críticas por cuanto que supone para algunos una vulgarización del elemento literario. Las jerarquías discursivas, en cambio, parecen haberse desmontado en esta nueva proliferación de mensajes hipercodificados que toman prestados elementos de otros discursos precedentes. Estamos en el territorio conceptual de lo que Bauman ha denominado como cultura líquida ${ }^{6}$ Es precisamente esa característica de la hipercodificación la que lleva a los creativos publicitarios a aprovechar canciones, textos, imágenes preexistentes para organizarlas en un mensaje complejo. El ensamblaje de esos elementos de naturaleza tan diferentes constituye un nuevo texto más complejo en su funcionamiento pragmático. Sin dejar de perseguir una función práctica tendente a vender y fomentar el consumo no renuncia a la elaboración estética. De ahí su naturaleza ambigua y ese carácter híbrido que socava los conceptos de arte y publicidad entendidos como prácticas bien diferenciadas. Lo paradójico de todo ello puede ser que canciones o incluso textos literarios se hagan más conocidos a través de un elemento tan poco esperable en la comunicación literaria como es el anuncio

\footnotetext{
${ }^{6}$ «La nuestra es una sociedad de consumo: en ella la cultura, al igual que el resto del mundo experimentado por los consumidores, se mantiene como un depósito de bienes concebidos para el consumo, todos ellos en competencia por la atención insoportablemente fugaz y distraída de los potenciales clientes, empeñándose en captar esa atención más allá del pestañeo [...] El principio del elitismo cultural es la cualidad omnívora: sentirse como en casa en todo entorno cultural, sin considerar ninguno como el propio, y mucho menos el único propio» (Bauman 2013:19)
} 
publicitario. Podría decirse así que la publicidad actúa también como un medio de transmisión que sirve para catalizar mensajes artísticos. En ocasiones, incluso, podría observarse lo que podría definirse como una decodificación aberrante desde el momento en el que un receptor puede recordar un anuncio por su estética, pero no por el producto anunciado. Lo que desde un punto de vista artístico resulta ser un éxito para el creativo, desde una óptica meramente práctica constituye un pequeño fracaso. En ese sentido podría argumentarse que la introducción de un elemento estético (ya sea una canción, un texto literario u otra referencia artística) fomenta una recepción, en el corto plazo del «aquí y el ahora», más intensa del anuncio ayudando a diferenciar el producto de otros muchos, pero, a largo plazo, contribuye a liberar el mensaje publicitario de ese olvido al que parece estar condenado una vez desvitalizada la función práctica para la que nació. Aquellos anuncios que nacieron con una marcada vocación estética y que desarrollaban una profunda emocionalidad sobreviven más tiempo en la memoria colectiva que se apoya, además, en la aparición de plataformas digitales de distribución de contenidos audiovisuales como YouTube. Cabría plantearse la hipótesis de que quizá esos anuncios híbridos de naturaleza estética acaban con el tiempo siendo enteramente obras de arte toda vez que el propósito práctico inicial se ha vuelto inoperativo. Esos textos se desenvuelven de forma natural en un entorno semiótico dinámico en el que los elementos que conforman el entramado cultural varían su posición en el sistema y cambian de consideración.

Por otro lado, se hace necesario también aludir a la recuperación de la importancia de las narraciones como vehículos privilegiados para ordenar el mundo e influir en los demás. Los relatos son efectivos para fomentar actitudes y se muestran mucho más contundentes que los argumentos racionales a la hora de convencer y doblegar voluntades. Frente a la lógica de la razón, impera la sinrazón de las emociones. Marc Gobé ha utilizado el concepto de emotional branding para definir las nuevas prácticas publicitarias. «Emotional branding provides the means and methodology for connecting products to the consumer in emotional way. It focuses on the most compelling aspect of human character; the desire to transcend material satisfaction, and experience emotional fulfillment. A brand is uniquely situated to achieve this because it can tap into the aspirational drive which underlines human motivation» (2001: xv). Son estas emociones un caballo de Troya que se van modelando en los relatos. Los anuncios publicitarios de manera paulatina van deslizando sus formas compositivas hacia usos narrativos. No importa ya tanto hablar de las bondades del producto 
anunciado sino construir una imagen basada en una serie de ideales. Consumir ya no es solo comprar; es integrarse en una forma de vida y hacerse partícipe de una escala de valores. Los relatos publicitarios comienzan a ser también un vínculo de unión para ir conformando una «tribu» que se identifique con una marca o un producto: un nuevo tótem de la modernidad. Precisamente sobre esta idea pivota el concepto del Storytelling entendido en el mundo publicitario como una fábrica de relatos para consolidar una marca. El reluciente prestigio de los logotipos parece haber alcanzado su fin y estos han perdido el aura que los rodeaba. Escribe Christian Salmon: «En menos de quince años el marketing ha pasado así del producto al logotipo, y luego del logotipo a la story; de la imagen de marca (brand image) a la historia de marca (brand story)» (2008: 57). Los relatos son la piedra angular para construir un mundo presidido por la marca. No son ya objeto estático de adoración sino fuente de un material narrativo que expande y modula su idea a través de infinitas historias: «No es que la mercancía y las marcas hayan desaparecido; están ahí, siempre igual de presentes, pero han perdido su estatus de objeto o de imágenes «cosificadas»: nos hablan y nos cautivan, nos cuentan historias que tienen que ver con nuestras expectativas y nuestras visiones del mundo» (2008:57). Algunas marcas han visto desestabilizada su imagen a través de relatos que denunciaban sus condiciones de explotación laboral en países del Tercer Mundo y se han visto urgidas a contrarrestar esa deriva con la creación de nuevos relatos que modifiquen esa imagen. Ante la crisis de las marcas el storytelling se convirtió en una máquina muy productiva para formatear la imagen de cara al consumidor. Cualquiera puede, además, fabricar un producto; lo esencial es gestionar su imagen. Las empresas vieron su mundo sometido a una crisis y la forma de superarla fue comenzar a contar historias. «Triunfaron las que construyen marcas, y se llegó a un nuevo consenso: los productos que tendrán éxito en el futuro no serán los que se presenten como «artículos de consumo», sino como conceptos: la marca como experiencia, como estilo de vida» (Klein 2001: 49). Al desplazar la manufactura a lugares que permitían reducir los costes de fabricación «las sedes centrales de las empresas tienen libertad para dedicarse al verdadero negocio: crear una mitología corporativa lo suficientemente poderosa como para infundir significado a estos objetos brutos imponiéndoles su nombre» (Klein 2001:49).

Podría verse de este modo una paulatina transformación de las prácticas publicitarias. Mediante esta metamorfosis la visualidad del logotipo deviene un relato; las campañas publicitarias se convierten, a su vez, en secuencias narrativas y el logotipo deriva 
en un personaje. La actividad publicitaria se integra dentro de un mundo pan-narrativo en el que los discursos se fraguan a modo de historias que activan las fibras más emocionales del consumidor para fidelizarlo. Muta así el estatus de la publicidad que pasa a sentirse muy cercana a las prácticas artísticas. Al Ries y Laura Ries afirmaban: «Like sculpture, painting and poetry, advertising is taking the same path. Advertising -said Marshall Mcluhan- is the greatest art form of the twentieth century» (2002:17)

La transformación de la publicidad que se camufla bajo la poética del relato y que absorbe elementos artísticos para construir su mensaje junto con la separabilidad del texto lírico de Kipling que ya había adquirido un estatus de enorme relevancia y lo habían convertido en un texto de culto dentro del acervo cultural común constituían los mimbres necesarios para que el poema «If» de Kipling encontrase un nuevo acomodo en el terreno publicitario.

\section{INTEGRACIÓN. KIPLING EN UN ANUNCIO DE REPSOL}

El spot que incluía el poema de «If» estaba producido por la Agencia de publicidad Young \& Rubicam que trabajó para Repsol desde 1996 hasta 2008. Esta agencia ha creado para Repsol anuncios de enorme plasticidad y capacidad emotiva. Pienso en la campaña «Inventemos el futuro» en cuyo spot televisivo una voz en off va desgranando todos los logros de la humanidad en el campo de la ciencia, tecnología y las artes. La música que la acompañaba era el piano del Ave María de Gounod. El ritmo que conseguía repitiendo insistentemente una idea lo acerca a los parámetros constructivos de la lírica y la asociación del discurso con las imágenes que se muestran no dista tanto de las prácticas de la poesía visual. Todo ese mensaje venía a enfatizar una línea que buscaba preservar la naturaleza y enlazar la imagen de la empresa petrolera con una visión ecologista. En otras ocasiones y como viene siendo habitual, Young \& Rubicam ha fortalecido esa alianza estratégica de Repsol con los valores del deporte del motor -relación que se inició en 1969- como se ve en el spot titulado «Gloria» en el que el apartado musical corre a cargo de una versión de la canción «Gloria» de Umberto Tozzi cantada por un coro que oficia a modo de público que celebra también la victoria de Dani Pedrosa. Será también Dani Pedrosa el que protagonice el anuncio de Repsol «Estela» (2008) en el que los pilotos anteriores de Repsol siguen su 
estela, dirigido por Nicolas Hollander. El propio Hollander será el encargado de dirigir el anuncio de Repsol en el que se incorpora el poema de Kipling «If» leído por el actor José Sacristán y cuyo telón de fondo es el tema musical de James Horner «Call to arms» de la banda sonora de la película Glory dirigida por Edward Zwick en 1989.

El anuncio se basaba en el aspecto visual de una serie de fotografías en las que aparecían pilotos como Hayden, Pedrosa, Marc Coma, Nani Roma todos ellos integrantes de equipos patrocinados por Repsol. Las imágenes fotográficas poseían un tiempo de exposición largo y la transición entre una y otra venía dictada por un fundido. Su tempo narrativo es lento incidiendo de este modo en el momento que se quiere destacar desde un punto de vista especialmente emotivo. Las escenas dejan ver tanto momentos de victoria como otros en los que la suerte es adversa y sobrevienen caídas y derrotas. Indudablemente, el texto de Kipling actúa como una brújula que orienta el sentido del anuncio publicitario y, a la vez, opera como un principio selectivo indicando qué instantáneas eran las que servirían como material narrativo para el spot publicitario. A su vez el spot actúa sobre el texto mutilando dos estrofas -la segunda y la cuarta- para adecuarlo a la duración estándar y también, quizás, debido a que su ausencia no se echa falta a la hora de enfatizar los valores de resistencia frente a la adversidad.

Esa templanza ante los contratiempos, que emana del poema de Kipling y que configura el espíritu del anuncio publicitario, contrasta en buena medida con otro spot de Repsol muy cercano en el tiempo y que llevaba aparejada la canción de Gloria. En este último parecen exaltarse los valores de la victoria mientras que el texto de Kipling describe un ideario radicalmente distinto y mucho más cercano al espectador por cuanto que no celebra la victoria épica del deportista sino que sitúa en una balanza de frágil equilibrio éxitos y fracasos. Este dato permite pensar que las campañas publicitarias vuelven al objeto publicitado dúctil en su escala de valores asociados. Es posible asociar una marca a la gloria de la victoria, pero también a la derrota y la importancia de creer en un mismo por encima de los resultados azarosos. Parece como si tanto la canción como el poema, elementos pre-existentes a los spots definieran las líneas maestras de estos inoculando una serie de valores en el mensaje publicitario.

Con ese espíritu relativista que pone en crisis la diferencia entre victoria y derrota que preconiza parte del poema de Kipling y que se postula como filosofía esencial del anuncio de Repsol se construye una suerte de relato implícito mediante la yuxtaposición de 
fotografías. Plantea una lógica débil, pero sobre la que puede ensayarse una lectura que, inconscientemente, despliega convenciones narrativas. Así, puede verse una fase en la que impera la adversidad y la derrota (que va unida a las imágenes que muestran las caídas y el sufrimiento experimentado por los diversos pilotos); a esta primera fase le sucede otra más relacionada con el desarrollo de una voluntad férrea frente a esa adversidad (en la que visualmente se ofrecen planos de los pilotos en carrera) y, finalizaría, con la alusión a la victoria como colofón (que rescatan imágenes de pilotos con un gesto de celebración). Implícita lleva una filosofía positiva que se adhiere a la imagen de la marca basada en la autoconfianza frente a la adversidad.

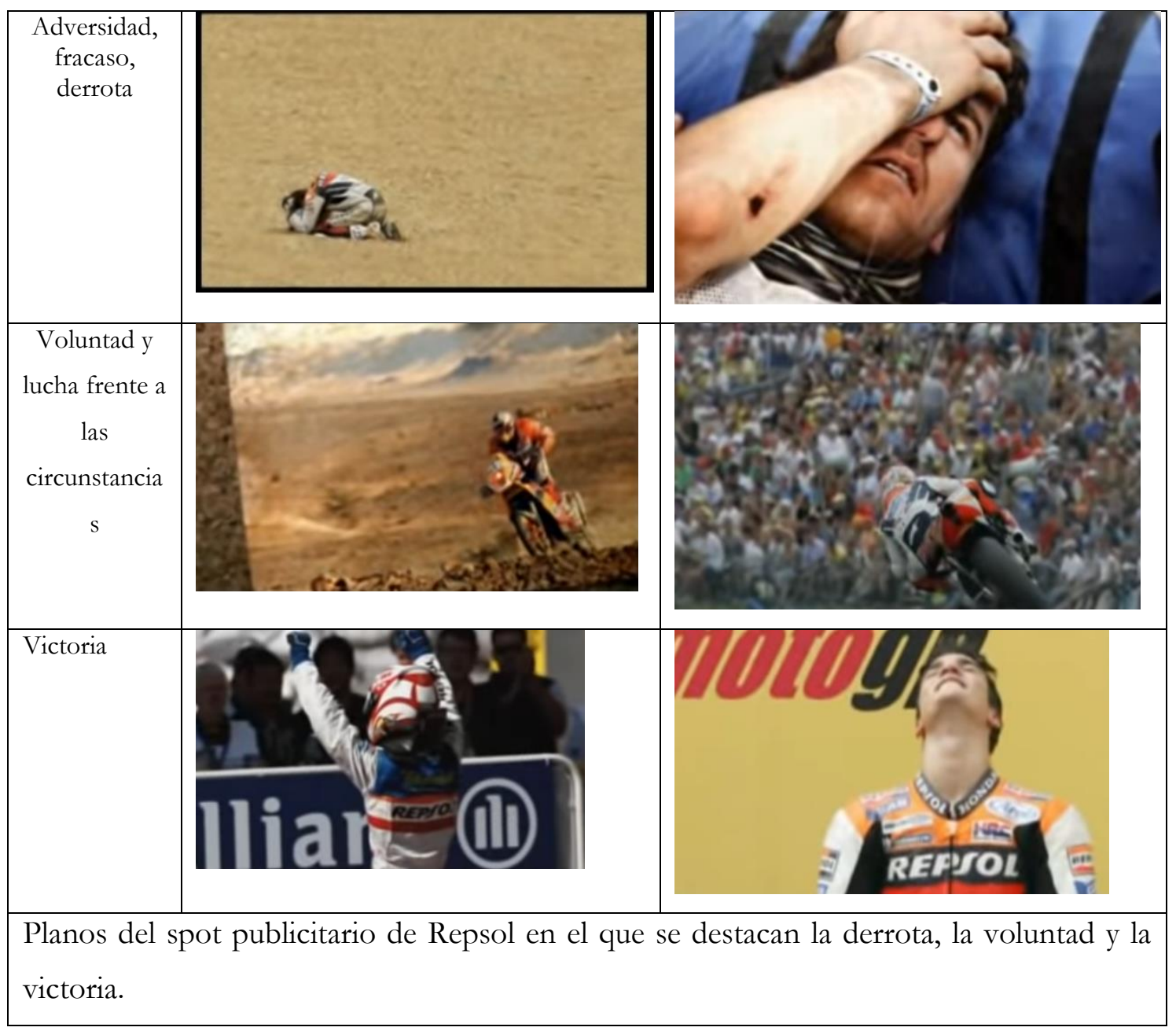

El poema de Kipling, así como la música de Horner (curiosamente es la misma que en el anuncio «Estela») junto con la voz de José Sacristán que transmite eficazmente la 
impresión de experiencia y firmeza ejemplares actúan como signos que connotan emocionalmente el mensaje. Crean una atmósfera que actúa como marco interpretativo para las imágenes que se muestran. Las imágenes de naturaleza fotográfica, que capturan un momento sobre el que se vierte una enorme significación al obligar a la mirada a detenerse en ese tiempo fugaz capturado ahora y convertido en algo duradero, se solapan y complementan. Ese haz de momentos reflejados al verse conjuntados traza un pequeño recorrido que permite entrever un hilo argumental. En cierto modo incorporan una lógica secuencial al estilo del cómic. En ese momento se puede apreciar el enorme interés que nace de la colaboración de esos diversos códigos constructivos que tienen a la imagen como piedra angular. Como se ha advertido la yuxtaposición de imágenes contiene una propuesta narrativa muy cercana sino idéntica a la práctica de la narración secuencial del cómic; sin embargo, el ritmo de lectura no lo impone el lector sino que viene dictado por el discurso cinematográfico que se vale de una duración determinada para cada plano y con ello establece un tempo narrativo determinado. En este caso el tempo, como se ha advertido, es lento y ello puede ser consecuencia de proyectar la poética fotográfica sobre el discurso cinematográfico. Si el cúmulo de imágenes podía atemperar y debilitar la fuerza expositiva y gráfica de la fotografía, los planos largos luchan contra esa tendencia a trivializar la imagen dotándola de protagonismo. La música y el poema actúan acentuando esa morosidad y saturándola emocionalmente.

Si en la estructura formal del anuncio puede observarse una voluntad férrea por resaltar lo estético, la intención publicitaria actuará creando una sutura entre la factura formal artística del anuncio y el propósito inicial de promoción. El eslogan final: «Nadie mejor para probar nuestros productos. Ahora, tú». Junto con la aparición del Logo de Repsol marca el territorio de manera definida. Es habitual que la publicidad no muestre sus cartas hasta la parte final del anuncio. Una vez creado el clímax final en el que el receptor puede hacer un balance de lo visto surge la identidad del supuesto emisor: Repsol y su invitación a comprar. Si esos pilotos, modélicos en su forma de actuar como intuimos gracias al poema de Kipling, han probado los productos de Repsol, ahora le toca al receptor de ese anuncio convertido en obra de arte que, súbitamente, se convierte en un comprador potencial.

En el territorio de los mensajes hipercodificados como son los publicitarios los diversos lenguajes actúan generando una sinergia de fuerzas. La naturaleza de los lenguajes es diversa y muy variada en su procedencia. Llama la atención que una empresa petrolífera y 
de lubricantes se valga en el siglo XXI de un poema publicado a inicios del siglo XX que fue escrito por un premio Nobel como Ruyard Kipling en circunstancias que no podían prever los usos futuros de ese texto. Algunos podrían pensar que se trata de una pérdida del aura artística del texto; otros verán en estas actuaciones nuevas posibilidades expansivas de lo literario y los lenguajes artísticos que, integrándose en una publicidad que es capaz de canibalizar un sinfín de discursos, acaba por asimilarse a las prácticas artísticas. Podría definirse este anuncio como un corto cinematográfico o como una performance lírico-visual que incide en lo humano que es fracasar. Cada propuesta en su nomenclatura hará vascular la balanza hacia un lado u otro. Por otro lado, la puesta en escena de ese poema de Kipling a través de la publicidad sirve para reconfigurar los posibles receptores de ese texto que pueden verse sorprendidos por un mensaje al que, en principio, por sus intereses, no pensaban llegar. En ese marco de cultura líquida esa mezcla variopinta no desentona sino todo lo contrario: es un síntoma de nuevos procedimientos de transmisión de mensajes que entran y salen dentro de aquello que podríamos denominar arte.

\section{El POEMA DE Kipling CONVERTIDo EN ÁLbUM ILUSTRADO: LA} RESISTENCIA A LA ASIMILACIÓN.

Dentro de esa lógica de los mensajes hipercodificados en la cultura líquida se muestra como crucial el principio de la recursividad de tal modo que cualquier texto puede ser nuevamente generado variando alguno de sus elementos. No es extraño que existan varias versiones de un videoclip musical o que los anuncios vuelvan una y otra vez sobre el mismo producto. Cualquier mensaje puede repetirse: su estructura modular así lo permite. Para el caso del poema «If» de Kipling resulta de interés examinar la aparición del álbum ilustrado realizado por Mauro Evangelista que convierte el poema a otro régimen discursivo. Posee la curiosidad de ser coetáneo del anuncio de Repsol: ambos son de 2007. El álbum ilustrado entendido como un género textual concebido en un principio para un público infantil ha ido ganando territorio y, sin dejar de presentar una mirada filtrada por esa naturaleza infantil, va convirtiéndose paulatinamente en un formato narrativo que demanda, además, un público adulto. Por otro lado, la utilización de textos literarios como espoletas que catalizan la aparición de un discurso gráfico es algo habitual. Baste recordar cómo todo libro infantil 
presenta un discurso gráfico que lo complementa y que añade valores al texto. Son muchos los textos que funcionan como base para la construcción de un álbum ilustrado. Sirvan como ejemplo el caso de Loren Long que recupera el poema de Walt Whitman para convertirlo en un álbum ilustrado. Peter Sis en su Coloquio de los pájaros recupera un poema persa de Farid ud-Din Attar; Javier Zabala, por su parte, transforma una carta de Vincent Van Gogh en El pájaro enjaulado y así muchos otros ejemplos ${ }^{7}$.

Evangelista realiza una traducción de la morfología del poema a la estructura del álbum ilustrado de tal modo que a cada estrofa del poema le corresponderá una doble página $^{8}$. En ese proceso de transformación podría decirse que Mauro Evangelista ejerce una operación de descomposición gráfica del poema de Kipling ya que su grafismo opera como un caleidoscopio que distorsiona la voz del poema en un haz temático y en un acabado cromático e iconográfico muy dispar. La voz monológica del poema se dispersa y el nuevo híbrido discursivo traza, gracias a la ilustración, puntos de fuga que actúan de forma centrífuga. La monolítica voz del emisor lírico se traduce en un inventario iconográfico muy variado que sirve para introducir en el texto una profunda red de referencias intertextuales. En cierto modo Evangelista lee el poema a través de otros textos y referencias mitológicas pero lo hace a través del intermediario de la imagen. En cada estrofa opera una síntesis conceptual: esa reducción es la que se traduce en una imagen que, las más de las veces, crea un puente con otra obra literaria. Si tomamos la segunda estrofa como ejemplo:
si puedes esperar sin que te canse la espera, si te injurian y no respondes a la mentira, si te odian y no cedes al odio, y, aun así, no pareces demasiado bueno ni hablas como un sabio

Esos cuatro versos se reducen a la primera idea enunciada: la espera. Tras esa reducción se produce una traducción visual que ha de encontrar una equivalencia gráfica para expresar el mismo concepto. Normalmente Evangelista acude a la tradición literaria o mitológica para hacerlo: en este caso será Penélope, el personaje de la Odisea [Imagen 2].

\footnotetext{
${ }^{7}$ Para una visión general sobre el álbum ilustrado lírico puede verse el trabajo de Rosario Neira Piñeiro (2012 y 2018). A pesar de que la construcción de un álbum ilustrado sobre un poema pre-existente o de escorar su esencia hacia lo lírico podría desestabilizar la idea básica del álbum ilustrado como género eminentemente narrativo no deja de ser cierto que bien pronto los álbumes se basaron en el aporte gráfico a textos en verso que ya existían. Pongo por caso el poema «My mother» de Ann Taylor que fue ilustrado por Peltro Williams Tomkins en 1807 y por Walter Crane en 1873 (Donelle Ruwe 2018).

${ }^{8}$ Sophie Van der Linden (2015) tiene en cuenta la doble página como unidad estructural básica del álbum ilustrado.
} 
Existe todavía un tercer momento en el que actúa la poética narrativa del álbum ilustrado. En esa doble página (marco de equivalencia gráfico-narrativo de las estrofas del poema) opera una tensión. Para el caso de este ejemplo se puede ver en la página par la figura de una Penélope mirando pensativa a través de una ventana el mar y el atardecer. De su regazo nace una estela interminable del traje de novia con el que consigue posponer su decisión de contraer nuevamente matrimonio. En la página impar figuran esos pretendientes que llevan delante de su rostro una máscara. Son dos universos (Penélope y sus pretendientes) enfrentados y cromáticamente también se establece una diferencia. La representación espacial no obedece a una necesidad realista, sino que incide en una disposición y una separación de eminente calado simbólico.

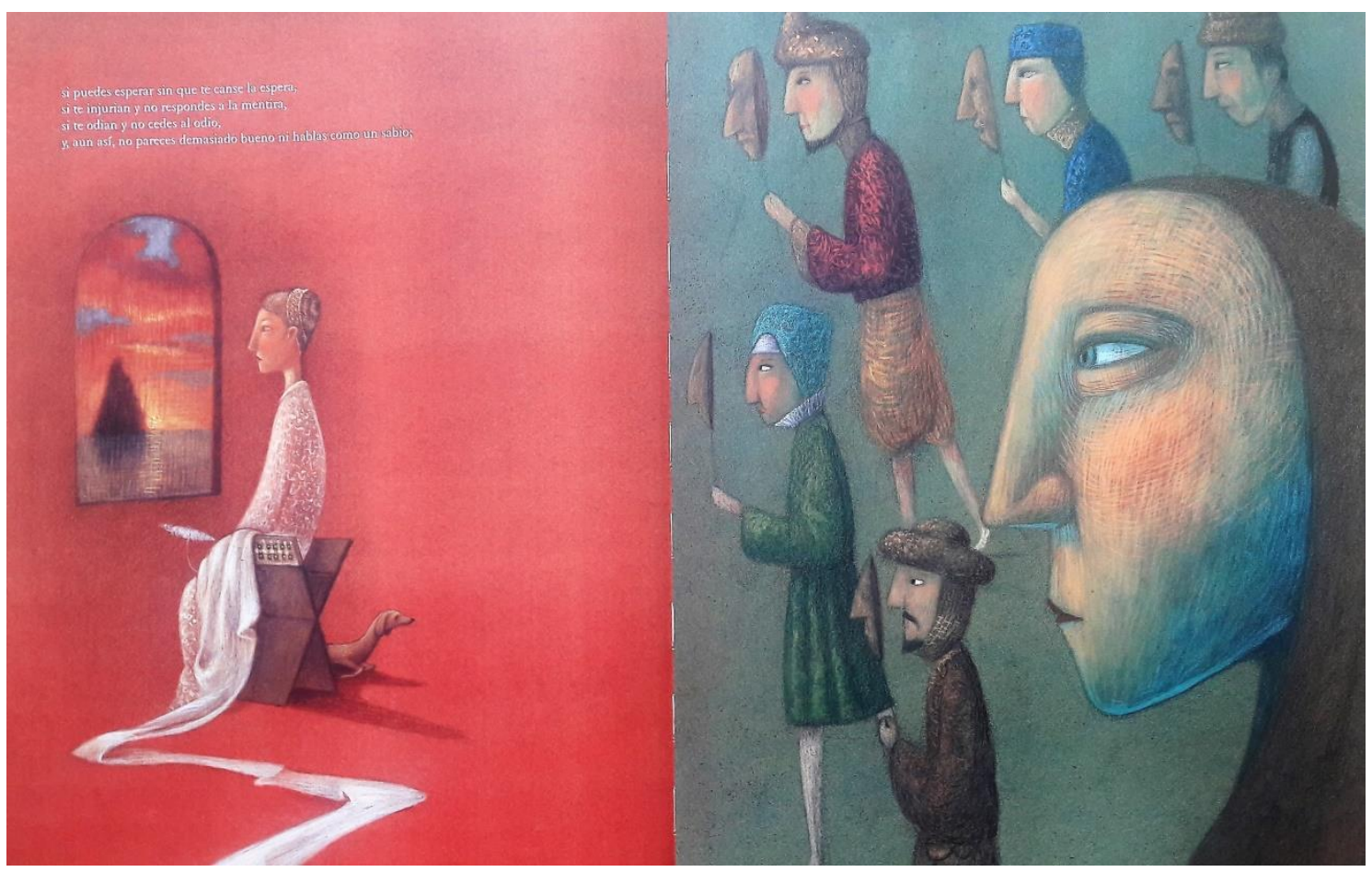

Imagen 2. Doble página de Carta a un hijo en el que se ven referencias a Penélope y sus pretendientes.

En ocasiones el suplemento gráfico que realiza Mauro Evangelista hace tomar al poema una dirección imprevista. Si nos fijamos en la tercera estrofa del poema:

si puedes soñar y no hacer de los sueños tu señor, si puedes pensar, y no hacer del pensamiento tu meta, si puedes encontrarte con el triunfo y la derrota y tratar de la misma manera a esos dos impostores 
veremos una realización gráfica inesperada si tenemos en cuenta las lecturas que había privilegiado la tradición. Esas menciones a la victoria y la derrota son uno de los puntos centrales sobre los que fijan su atención las lecturas pasadas y son las que han posibilitado la adscripción de los valores del deporte. No hay que olvidar que Kipling había enraizado el poema en una circunstancia bélica pero pronto el poema giró hacia esa visión que privilegiaba la deportividad. El anuncio de Repsol había utilizado, precisamente, esta idea como puente para conectar la esponsorización que ejerce con el mundo del motor con una filosofía muy determinada que encontraba en el poema de Kipling la expresión lingüística exacta para conformar el modelo de comportamiento que se quería transmitir. Sin embargo, Evangelista esquiva esa idea y en su proceso de reducción conceptual de cada estrofa atiende más a la idea del «sueño» que a la del frágil equilibrio entre victoria y derrota. En la página par aparecerá dibujada la luna con unos rasgos humanizados mientras que en la página impar en una geografía urbana aparecen poetas, niños y gatos como seres que acaban encandilados con la visión del astro [Imagen 3]. El propio autor declara la relación que existe entre el texto y su ilustración: «Los sueños están ligados a la poesía y a la luna. Poetas, niños y animales son los únicos capaces de mirarla siempre a la cara». La vía épico-deportiva sufre una retracción en la lectura que supone la ilustración de Mauro Evangelista. El ilustrador italiano ha decidido traer a un primer plano otros elementos que parecían secundarios: la capacidad de ensoñación. Frente a la visión épica del anuncio de Repsol, Evangelista privilegia la visión onírica e imaginativa que incide más en lo puramente lírico que en la ética que había sido asociada al poema. De algún modo la ilustración abunda en lo primigenio del texto lírico y desmonta el carácter moral que parecía imperar en él. No son solo instrucciones de comportamiento sino materia musical hecha lenguaje que ahora se traduce a imágenes. 


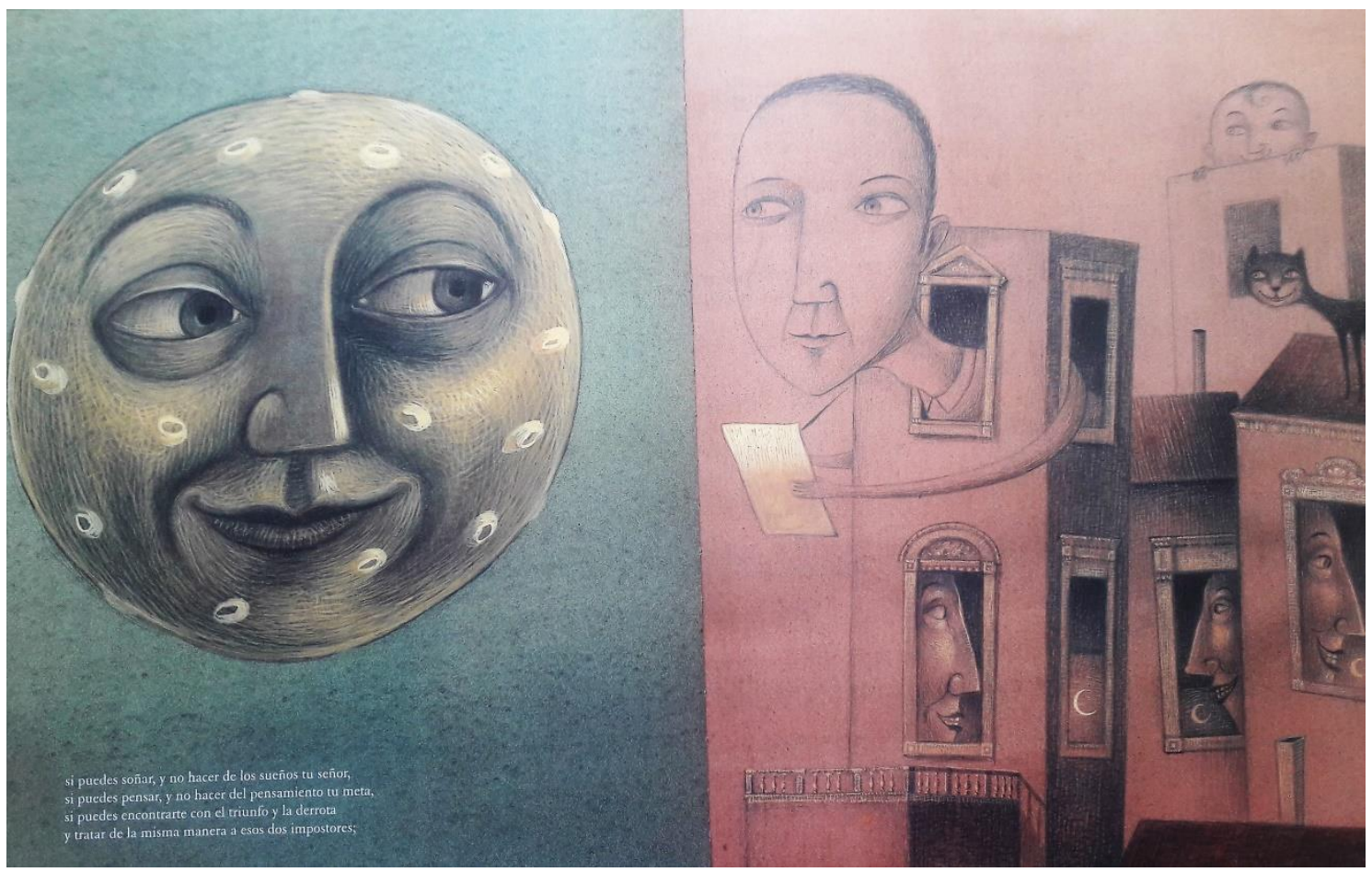

Imagen 3. Doble página de Carta a un hijo en la que la luna representa los sueños.

Ya se ha advertido cómo la ilustración crea una abertura de los versos de Kipling hacia otros textos: la imagen es una forma de lectura intertextual que en ese caso se superpone sobre el texto enriqueciéndolo con nuevos sentidos. No se trata de una intertextualidad basada en la cita al pie de la letra. En esa relación asimétrica entre palabra e imagen había que encontrar un mecanismo de equivalencias semánticas que ya se ha insinuado anteriormente. Ese mecanismo pasa por encontrar imágenes que son portadoras de una idea: son estereotipos que se explotan en su capacidad simbólica. Por esa razón el dibujante no se ve prisionero de la tradición mitológica. La ilustración que acompaña a la séptima y penúltima estrofa sirve para mostrar cuanto digo. Los versos de Kipling conminan a no envanecerse al hablar con las multitudes y a no perder el sentido común en compañía de los poderosos. La traducción gráfica echa mano de la figura de Ícaro y de las Erinias que le recuerdan que sigue siendo un hombre. No existen textos que conecten estos dos grupos de personajes; no importa porque no se pretende una re-creación del relato mitológico sino tan solo hacerlos portadores de ese valor simbólico en el que Ícaro es el símbolo de la soberbia que es reconducida por el trío de las Furias o Erinias. 
Podría, pues, decirse que Evangelista opera sobre el poema de Kipling buscando una serie de equivalencias estructurales, conceptualizando el poema y traduciéndolo gráficamente, enriqueciéndolo semánticamente a través de lecturas cruzadas y atemperando de algún modo el carácter moral para enfatizar lo plástico. Cada estrofa se descompone en una serie de microrrelatos visuales que simplifican (reducción conceptual) y a la vez amplían (lectura intertextual) el original de Kipling. Todo ello venía amparado por la idea de la proximidad que puede mantenerse entre el álbum ilustrado y el texto poético. Su intensidad semántica, la capacidad simbólica, el ritmo que se impone en la lectura son rasgos que acercan a estos dos géneros.

\section{CONCLUSIONES}

En conclusión podría advertirse que el poema de Kipling se ha convertido en un texto de culto que se revisita una y otra vez de manera constante ${ }^{9}$. Posee una fuerza moral y se ve asociado a una serie de valores emocionales desde el momento en el que se asienta sobre un esquema enunciativo que va tiene como protagonistas al padre (emisor) y al hijo (receptor). Los creativos de Young \& Rubicam incidieron en la asociación de valores deportivos que ya desde los años 30 había adquirido y buscaban una neutralización entre los discursos integrados en el arte y aquellos que estaban fuera de ese perímetro. Al incluir el poema en un complejo semiótico como es el anuncio publicitario de naturaleza audiovisual se operaba una profunda metamorfosis que le llevaba incluso a la omisión de dos de sus ocho estrofas. Se trata de uno de los «usos» que surgen de la apropiación del texto para propósitos inesperados. Kipling nunca pudo prever que acabaría anunciando lubricantes y gasolinas. Esa «remediación» del poema, convertido en parte de un spot suponía un radical cambio contextual y la inserción de funciones nuevas. Como consecuencia de ello el poema se asocia a un producto y se borra en cierto modo la autoría de Kipling en favor de la imagen omnipotente del anunciador: en este caso Repsol. El anuncio acaba «estetizándose»y, de

\footnotetext{
${ }^{9}$ Resulta interesante la posibilidad de aludir al posible destinatario del texto. El poema de Kipling iba inscrito en un contexto editorial dirigido principalmente a los niños. Pronto puedo verse en él una fuente de autoridad moral que lo hacía apropiado para la lectura de adultos. Su reconversión en otros lenguajes, anuncios publicitarios, álbumes ilustrados e incluso versiones musicales garantizan una variabilidad constante de públicos. Por otra parte, hay que tener en cuenta cómo ciertos textos de la literatura para adultos en su reconversión a álbumes ilustrados poseen una audiencia ambivalente (Zöhrer 2018). Esta idea puede ponerse también en relación con el surgimiento de los denominados como crossover picturebooks (Beckett 2009).
} 
modo paralelo, el poema pierde parte de su «aura» artística funcionando de modo práctico y sirviendo como voz para vender un producto. Está supeditado a una función superior y su naturaleza lírica sirve para singularizar un mensaje publicitario que pretende vender. Otra práctica es la que lleva a cabo Mauro Evangelista. Su «remediación» no traslada al texto a un terreno fronterizo, como lo hacía la publicidad, sino que lo mantiene dentro de un régimen discursivo que sigue perteneciendo a la literatura. En este sentido es respetuoso con el texto; de ahí que sería inconcebible que en su transformación en álbum ilustrado se omitiese parte del texto (tal y como sucedía en la publicidad). El texto poético de Kipling no se «usa» sino que, siguiendo los términos de Umberto Eco se interpreta realizando un enriquecimiento intertextual gracias a la intermediación de la imagen ${ }^{10}$. Ya no está supeditado a un fin superior, sino que entabla un diálogo con el suplemento gráfico que añade Evangelista. Por otro lado, el hecho de ilustrar el poema ofrece la posibilidad de legitimarlo editorialmente. Al ilustrarse, el poema se convierte en fetiche editorial ya que el discurso gráfico nace del texto y lo complementa creando relaciones imprevistas. Lo gráfico supone una lectura personal del poema y le da la oportunidad de editarse por separado. La ilustración permite al poema convertirse en libro-objeto con una identidad visual definida que pugna por hacerlo resistir frente a la fagocitación digital a la que la literatura se ve abocada. El álbum ilustrado no es fácilmente traducible a la pantalla de un ebook. Su materialidad reclama la belleza del objeto por encima de la función de ser un mero soporte de información. Podrían verse en la ilustración y la conversión a formatos gráficos como el álbum ilustrado estrategias para conseguir una forma refractaria a la absorción digital de la literatura. Un cuento puede tomar nueva vida acompañado de nuevas ilustraciones; un poema suscita el despliegue de una belleza visual que traspasa las imágenes para impregnar toda la factura del libro.

La lectura no es una actividad inocente sobre todo en una época en la que los discursos establecen nuevas formas de contacto. Cada texto arrastra el peso de las interpretaciones y valores con los que se ha cargado. Las remediaciones de textos pueden introducir en su ADN sentidos extraños, propósitos alejados de la actividad estrictamente artística que disparan su sentido en múltiples direcciones e inauguran circuitos de circulación cultural sorprendentes. La publicidad puede ser una lanzadera para dar a conocer a Kipling. Quizá muchos hayan atendido al anuncio porque les sorprendió el poema leído por Sacristán. Para el caso concreto de las dos remediaciones que hemos analizado del poema de Kipling

10 Para una visión acerca del «uso» e «interpretación» de los textos líricos (Trabado 2002: 13-23) 
podrían definirse operaciones de sesgo bien diferente que tienen que ver con una integración (anuncio de Repsol) y una resistencia a la asimilación (álbum ilustrado). En todo caso parece evidente que existen, pues, brechas en la comunicación literaria en la que se plantean hiatos que despertarán la susceptibilidad de los guardianes de la vieja cultura. Algunos preferirán denominarlo como «vulgarización» de la cultura; otros verán una forma de «democratización» y nuevas posibilidades de actuación para el arte más allá de los márgenes que la tradición tenía asignada para este lenguaje. Integración y resistencia son formas de seguir haciendo hablar a un poema. Sigue siendo, en todo caso, una coartada para hablar de lo que emociona al hombre. 


\section{BIBLIOGRAFÍA}

Bauman. Zygmunt (2013): La cultura en el mundo de la modernidad líquida, México, Fondo de Cultura Económica.

Beckett, Sandra (2009): Crossover Picturebooks. A Genre for All Ages, Nueva York, Londres, Routledge.

Bolter, Jay y Richard Grusin (2002): Remediation. Understanding New Media, Londres, Cambridge, The MIT Press.

Cercas, Javier (2007): «La chispa de la vida», en El país 20 de abril de 2007. https://elpais.com/diario/2007/04/22/eps/1177222556_850215.html [10 de mayo de 2019].

Cruz, Juan (2013): «Marsillach y el poema If de Kipling», en Blogs. Cultura. El País 26 de enero. https://blogs.elpais.com/juan_cruz/2013/01/marsillach-y-el-poema-if-dekipling.html

Cruz, Juan (2016): El territorio de la memoria y otras novelas autobiográficas, Barcelona, Debolsillo. Escribano Hernández, Asunción (2011): Literatura y publicidad. El elemento persuasivo-comercial de lo literario, Zamora, Comunicación Social.

Evangelista, Mauro (2008): Carta a un hijo, Zaragoza, Edelvives.

Gobé, Marc (2001): Emotional Branding. The New Paradigm for Connecting Brands to People, Nueva York, Allwrothpress.

Gil González, Antonio J. (2012): +Narrativa(s): Intermediaciones novela, cine, cómic y videojuegos en el ámbito hispánico, Salamanca, Universidad de Salamanca.

Hollander, Nicolás (2007): «If» anuncio Repsol. Young \& Rubiccam.

Kipling, Ruyard (2013): Something of Myself and Other Autobiographical Writings, Cambridge, Cambridge University Press. 
Klein, Naomi (2001): No logo. El poder de las marcas, Barcelona, Paidós.

Mazza, Nicholas (2003): Poetry Therapy: Theory and Practice, Nueva York y Hove, BrunnerRoutledge.

Neira Piñeiro, María del Rosario (2012): «Poesía e imágenes: una nueva modalidad de álbum ilustrado», en Lenguaje y textos, 35: 131-138.

Neira Piñeiro, María del Rosario (2018): «Posibilidades de secuenciación de las imágenes en el álbum ilustrado lírico», en Ocnos. Revista de Estudios sobre lectura, 17 (1): 55-67.

Pennycook, Alastair (2017): The Cultural Politics of English as an International Language, Londres, Routledge.

Ries, Al y Laura Ries (2002): The Fall of Advertising \& the Rise of PR. Nueva York, HarperCollins Pubishers.

Ruwe, Donelle (2018): «Poetry in Picturebooks», en Bettina Kümmerling-Meibauer ed. The Routledge Companion to Picturebooks, Londres, Routledge: 246-259.

Salmon, Christian (2008): Storytelling. La máquina de fabricar historias y formatear las mentes, Barcelona, Península.

Sánchez Mesa, Domingo y Jan Baetens (2017): «La literatura en expansión. Intermedalidad y transmedialidad en el cruce entre la Literatura Comparada, los Estudios Culturales y los New Media Studies», en Tropelías 27: 6-27.

Scolari, Carlos A. (2013): Narrativas transmedia. Cuando todos los medios cuentan, Barcelona, Deusto.

Trabado Cabado, José Manuel (2002). La lectura lírica. Asedios pragmáticos a textos poéticos, León, Universidad de León.

Van Der Linden, Sophie (2015): álbum [es]. Ekaré, Banco del Libro.

Young, James O. (2008): Cultural Appropriation and the Arts. Oxford, Malden, Blackwell Publishing.

Zöhrer, Marlene (2018): «Picturebooks and Adaptations of World Literature», en Bettina Kümmerling-Meibauer (ed.) The Routledge Companion to Picturebooks, Londres, Routledge: 485-494. 
SOBRE EL AUTOR

\section{José Manuel Cabado Trabado}

Profesor titular del área de Teoría de la Literatura y Literatura Comparada. Universidad de León. Desde la dirección del Servicio de Publicaciones de la Universidad de León ha impulsado la creación de la colección Grafikalismos dedicada a estudiar los lenguajes gráficonarrativos como son el cómic y el álbum ilustrado. Es el investigador principal del «Grupo de Estudios sobre Cómic y Narración Gráfica (GRECONAGRA)» y dirige el proyecto de investigación «La evolución de los lenguajes gráfico-narrativos y su relación con el público lector»: fruto de este proyecto son las publicaciones de los libros colectivos que ha coordinado: Género y conciencia autoral en el cómic español (1970-2018) (Universidad de LéonEolas Ediciones) y Encruiciadas gráfico-narrativas. Novela gráfica y álbum ilustrado que aparecerá en la editorial Trea.

Contact information: Email: jmtrac@unileon.es 